\title{
Endobronchial Lesion
}

National Cancer Institute

\section{Source}

National Cancer Institute. Endobronchial Lesion. NCI Thesaurus. Code C92486.

A benign or malignant lesion that arises within the bronchial wall. 